\title{
Phosphorus removal in low alkalinity secondary effluent using alum
}

\author{
R. J. Banu; K. U. Do; *I. T. Yeom \\ Department of Civil and Environmental Engineering, Sungkyunkwan University, 300, Chunchun-dong, Jangan-gu, \\ Suwon-Si, 440-746, Korea \\ Received 16 May 2007; revised 7 August 2007; accepted 25 October 2007; $\quad$ available online 26 December 2007
}

\begin{abstract}
The alkalinity plays an important role in phosphorus removal using coagulant. The dosage of coagulant in the low alkalinity wastewater is limited due to rapid $\mathrm{pH}$ changes. In the present study, a series of jar test was conducted using low alkalinity wastewater $(50 \mathrm{mg} / \mathrm{L})$ to evaluate the optimum $\mathrm{pH}$, dosage and performance parameters (slow mixing and settling time) for the common coagulant alum. From the experiment, it was found that the dosage of coagulant and removal of phosphorus depend upon the $\mathrm{pH}$ of the wastewater after adding coagulant. The final optimum $\mathrm{pH}$ for efficient $\mathrm{P}$ removal was found to be within the range of 5.7-5.9. This range acts as an indicator and it is the maximum tolerable $\mathrm{pH}$ range for phosphorus removal for low alkalinity wastewater. The optimum time for slow mix and settling was found to be $20 \mathrm{~min}$. The optimum mole ratio of alum to remove one mole of phosphorous was found to be 2.3. The alum coagulation at $\mathrm{pH} 7$ produced effluent with the total residual phosphorus and reactive phosphorus content of 0.3 and $0.9 \mathrm{mg} / \mathrm{L}$, respectively.
\end{abstract}

Key words: Alum, phosphorous, coagulation, $\mathrm{pH}$, secondary effluent

\section{INTRODUCTION}

Phosphorus present in domestic wastewater is an important macro-nutrient for plant and microorganisms growth. The discharge of large quantities of this nutrient into natural receiving sources raises the growth of algae and results in eutrophication of lakes and streams (Mervat and Logan, 1996). In fact, algae may grow at $\mathrm{PO}_{4}^{3-}$ levels as low as $0.05 \mathrm{mg} / \mathrm{L}$ (Stanley, 2001). But fortunately, its growth can be inhibited at the levels of $\mathrm{PO}_{4}^{3-}$ well below $0.5 \mathrm{mg} / \mathrm{L}$ (Stanley, 2001). Phosphorus is found in wastewater in three principal forms: orthophosphate ion, polyphosphates or condensed phosphates and organic phosphorus compounds (Mahmut and Ayhan, 2003). The phosphorus concentrations in secondary effluent stand usually within the range of 3-7 mg/L, which mostly consist of orthophosphate and about $1 \mathrm{mg} / \mathrm{L}$ of organic phosphorus (Clark, et al., 1997 and Sedlak, 1991). Thus, it is necessary to reduce the concentration of phosphorus in secondary wastewater to prevent the algal bloom. Actually, phosphorus removal techniques fall into three main categories: physical, chemical and biological (Wang, et al., 2006). Among them, chemical removal techniques, using metal salts, are reliable and well-established processes (Yeoman, et al., 1988;

ه*Corresponding Author Email: yeom@skku.edu

Tel.: +82 3129966 80; Fax: +82312996693
Wang, et al., 2005 and Lee, et al., 2003). Chemically, phosphate is most commonly removed by precipitation. Precipitation processes are capable of at least $90-95 \%$ phosphorus removal at a reasonable cost (Paul, et al., 2001). Numerous substances have been used as coagulants, including $\mathrm{Al}_{2}\left(\mathrm{SO}_{4}\right)_{3} \cdot 18 \mathrm{H}_{2} \mathrm{O}, \mathrm{FeCl}_{3} \cdot 6 \mathrm{H}_{2} \mathrm{O}$, $\mathrm{Fe}_{2}\left(\mathrm{SO}_{4}\right)_{3}, \mathrm{FeSO}_{4} \cdot 7 \mathrm{H}_{2} \mathrm{O}$ and $\mathrm{Ca}(\mathrm{OH})_{2}$ (Metcalf and Eddy, 1993). In general, the degree of phosphorus removal by chemical precipitation is affected by many factors, such as $\mathrm{pH}$, alkalinity, coagulant dose, speed of flash mixing and other interfering substances (James, et al., 2003). In case of low alkalinity wastewater, the $P$ removal by coagulation is very difficult because of the rapid change that the $\mathrm{pH}$ undergoes after adding the coagulant. The overall objective of this study is to find an indicator for optimum coagulant addition and mole ratio for alum to remove phosphorous efficiently from the low alkalinity wastewater.

\section{MATERIALS AND METHODS}

The secondary effluent used was collected from a domestic wastewater treatment plant in Suwon city, Korea. The wastewater was collected after the activated sludge treatment process. The characteristics of the secondary wastewater are given in Table 1 . The coagulation experiments carried out using $\mathrm{Al}_{2}$ 
$\left(\mathrm{SO}_{4}\right)_{3} \cdot 18 \mathrm{H}_{2} \mathrm{O}$ which have been used widely for phosphorus removal.

The coagulation experiments were carried out at the laboratory temperature $\left(20 \pm 2{ }^{\circ} \mathrm{C}\right)$ using a Jar-test (Model SJ-10, Young Hana Tech. Co., LTD) with a six paddle stirrer. In each of the tests, $1000 \mathrm{~mL}$ of secondary effluent was taken in the jar. The $\mathrm{pH}$ was adjusted to the desirable level with the addition of alkali $(1 \mathrm{~N} \mathrm{NaOH})$ or acid $(0.1 \mathrm{~N} \mathrm{HCl})$. The coagulant was added under stirring. Rapid mix took place for $1 \mathrm{~min}$. at a speed of $200 \mathrm{rpm}$, followed by slow mix for $30 \mathrm{~min}$. at $30 \mathrm{rpm}$. The effects of slow mixing on TP removal were carried out at varying times, namely 5, 10, 15, 20, 25 and 30, respectively. The settling period lasted for $30 \mathrm{~min}$.

After the settling period, samples were taken and analyzed immediately for $\mathrm{pH}$, phosphorus, COD and TSS. The $\mathrm{pH}$ of the samples was measured with Horiba Navi at $\mathrm{pH}$ meter F-54. COD, phosphate and reactive phosphorus were analyzed using Hach spectrophotometer. The other parameters in the sample were analyzed employing the methods described in APHA (2005) in detail.

\section{RESULTS AND DISCUSSION}

The influence of $\mathrm{Al}_{2}\left(\mathrm{SO}_{4}\right)_{3} \cdot 18 \mathrm{H}_{2} \mathrm{O}$ dosage on phosphorus removal during the coagulation was shown in Fig. 1. The addition of 1 mole of alum in water will consume 6 moles of bicarbonate alkalinity which resulted in the drop of $\mathrm{pH}$ (Vernon and David, 1980). Since the wastewater is having low alkalinity (50 mg/L), the $\mathrm{Al}_{2}\left(\mathrm{SO}_{4}\right)_{3} \cdot 18 \mathrm{H}_{2} \mathrm{O}$ dosage plays an important role in phosphorus removal. For example, in case of $\mathrm{pH} 7$, a raise in $\mathrm{Al}_{2}\left(\mathrm{SO}_{4}\right)_{3} \cdot 18 \mathrm{H}_{2} \mathrm{O}$ dosage increases the phosphorus removal up to $80 \mathrm{mg} / \mathrm{L}$. Further, an increase in the dosage leads to the decrease in phosphorus removal efficiency. The decrease in phosphorus removal efficiency after the optimum dosage was due to the restabilization of colloidal suspension (Pinotti and Zaritizky, 2001; Ahmad, et al., 2006). Even though the precipitation reaction occur well in the optimum pH range of 5.8 to 6.5 (De Hass, et al., 2000), the phosphorus removal efficiency decreases for $\mathrm{pH} 6$ at very low dosage $(20 \mathrm{mg} / \mathrm{L})$. This is due to the fact that an increase in the dosage shifts the optimum $\mathrm{pH}$ to an unfavorable range for phosphate removal. The alum dosage at $\mathrm{pH} 5$ and 4 does not have a major influence in phosphorous removal. In case the $\mathrm{pH}$ range is below 5.5, the hydration of alum does not proceed. In addition, the formation of insoluble $\mathrm{AlPO}_{4}$ is not favored as AlPO is solubilized below pH 6. For pH 8 and 9, the phosphorus removal efficiency increases with a dosage increase up to 130 and $140 \mathrm{mg} / \mathrm{L}$. From the above, it is evident that in low alkalinity wastewater, the alum dosage needs alkalinity supplementation to achieve a residual TP of below $0.1 \mathrm{mg} / \mathrm{L}$. The mere increase in the dosage is meaningless and it actually decreases the performance of the coagulant.

The influence of $\mathrm{pH}$ on phosphorus removal was depicted in Fig. 2. Phosphate removal by aluminum phosphate highly depends upon the $\mathrm{pH}$ of the wastewater (Lujubinko, et al., 2004). After $\mathrm{Al}_{2}\left(\mathrm{SO}_{4}\right)_{3} \cdot 18 \mathrm{H}_{2} \mathrm{O}$ was added into the wastewater, the $\mathrm{pH}$ of the solution decreased. This is due to the fact that a part of alum was precipitated as the hydroxide forms and $\mathrm{H}^{+}$was formed in water by the following reaction:

$\mathrm{Al}^{3+}+3 \mathrm{H}_{2} \mathrm{O} \rightarrow \mathrm{Al}(\mathrm{OH})_{3} \downarrow+3 \mathrm{H}^{+}$(Plaza, et al., 1997). After adding coagulant, the $\mathrm{pH}$ of the wastewater was more important than its initial $\mathrm{pH}$ for low alkalinity wastewater. Because in low alkalinity wastewater, after the addition of coagulant, the $\mathrm{pH}$ will drop rapidly and shift the $\mathrm{pH}$ optimum very fast resulting in decreased performance even in the optimum $\mathrm{pH}$ range (6-7) recommended in the literature for efficient phosphorus removal. For example, in case of $\mathrm{pH}$ 6, the phosphorus removal was high at low dosage $(10 \mathrm{mg} / \mathrm{L})$ when compared to that of remaining $\mathrm{pH}$, namely $7,8,9$ and 10 . The subsequent increase in the dosage resulted in a decrease in the phosphorus removal for $\mathrm{pH} 6$ rather than others. This is due to the rapid shifting of $\mathrm{pH}$ by alum dosage. In the $\mathrm{pH} \mathrm{6,} \mathrm{7,} \mathrm{8,} 9$ and 10 used for coagulation, the residual phosphorus in the wastewater decreases to the range of 5.7 to 5.9. Further, this decrease in the $\mathrm{pH}$ level resulted in an increase in the residual phosphorus concentration, whereas the pH 4 and 5 did not play any role in the phosphorus removal. Regarding this, it is clear that the maximum tolerable $\mathrm{pH}$ range for low alkalinity wastewater to remove phosphorus falls between $\mathrm{pH} 5.7$ and 5.9. This range acts as an indicator that a further addition of coagulant at this range resulted in a decrease in the phosphorous removal efficiency. The best place to remove the phosphorus from wastewater by $\mathrm{AlPO}_{4}$ precipitation would be near to the tolerable $\mathrm{pH}$ range (6-7). It is evident from Fig. 2 that the removal of phosphorus at low dosage was higher for $\mathrm{pH} 6$ and 7 than the rest of the $\mathrm{pH}$. The presently observed 


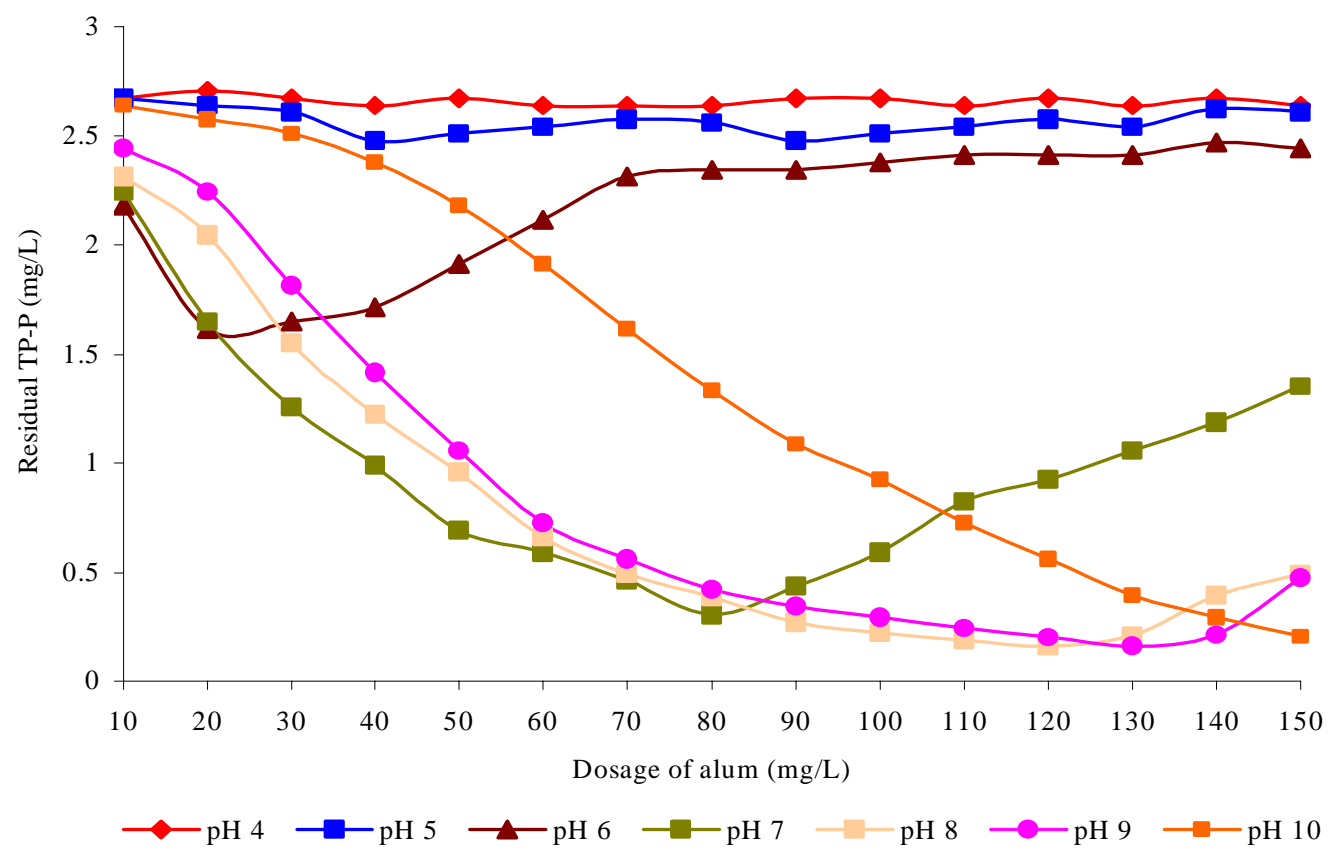

Fig. 1: The influence of alum dosage on TP-P removal during the coagulation

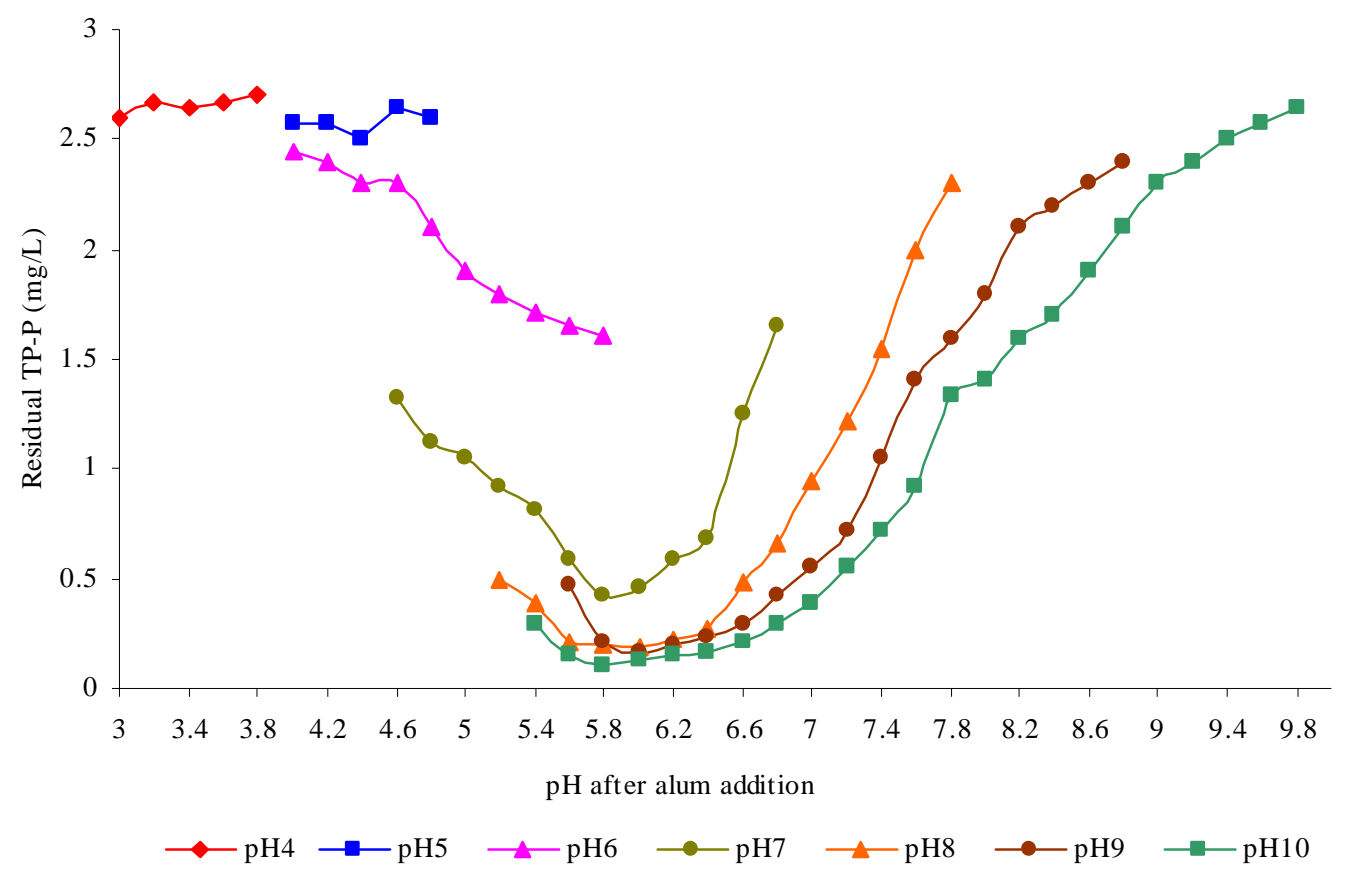

Fig. 2: The influence of $\mathrm{pH}$ on TP-P removal during alum coagulation 


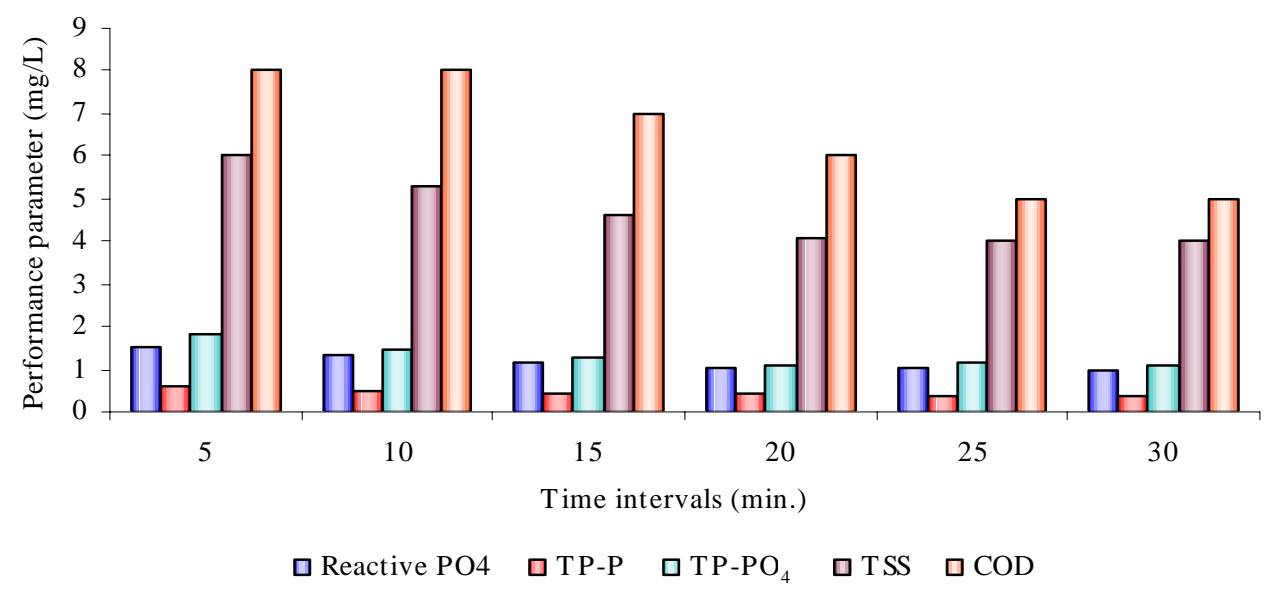

Fig. 3: The effect of slow mixing on the performance parameters during alum coagulation

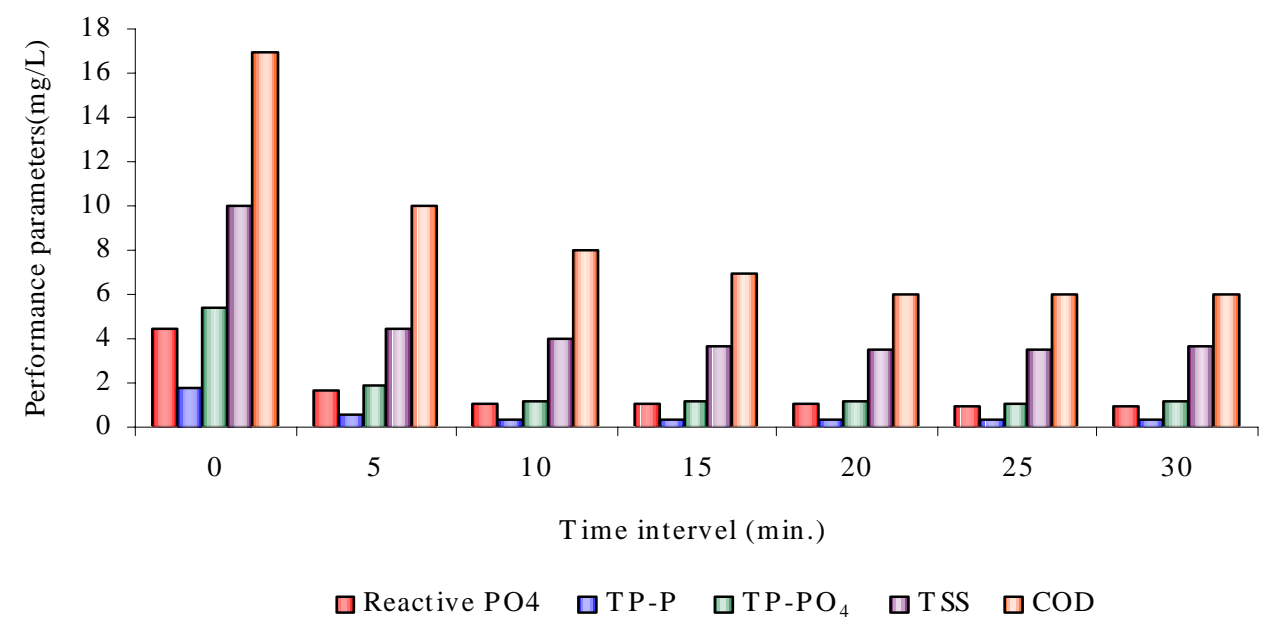

Fig. 4: The effect of settling time on the removal of performance parameters during alum coagulation

optimum $\mathrm{pH}$ range of 6-7 was similar to the findings of Georgantas and Grigoropoulou, (2006). Even though the removal of phosphate was higher for $\mathrm{pH} 6$ at low dosage (10 mg/L), pH 7 was selected for the next set of experiments. pH 7 was selected because it possibly brings down the TP value below $0.5 \mathrm{mg} / \mathrm{L}$, which is essential to arrest the algal growth (Robert, et al., 2003).

Slow mixing is one of the important processes in coagulation, facilitates the formation of micro-particles and enhances the settling (Muller and Palonen, 2002).

The present study aims at reducing the time needed for slow mixing. After the $30 \mathrm{~min}$. settling, the samples were analyzed for TP, COD and TSS. Fig. 3 shows the effect of flocculation mixing time on the phosphorus removal; TSS and COD are at an alum dosage of 70 $\mathrm{mg} / \mathrm{L}$. It is evident from Fig. 3 that TP removal was not affected by slow mixing, whereas COD and TSS removal stabilized after $15 \mathrm{~min}$. of slow mixing. The reason why may be due to the fact that the phosphorus removal was associated with precipitation, whereas COD and TSS removal were associated with small particles formation (Georgantas and Grigoropoulou, 2006). Since the variation of TP, COD and TSS is not significant after $20 \mathrm{~min}$. of slow mixing, further experiments were carried out during $20 \mathrm{~min}$. of slow mixing at $30 \mathrm{rpm}$.

The effect of settling time on the removal efficiencies of TP, COD and TSS was also examined. During this study, the following parameters were maintained: 200 rpm for 1min. (rapid mixing) and $30 \mathrm{rpm}$. for $20 \mathrm{~min}$. (slow mixing). The samples were collected at different settling times, namely 0, 5, 10, 15, 20, 25 and $30 \mathrm{~min}$. and 


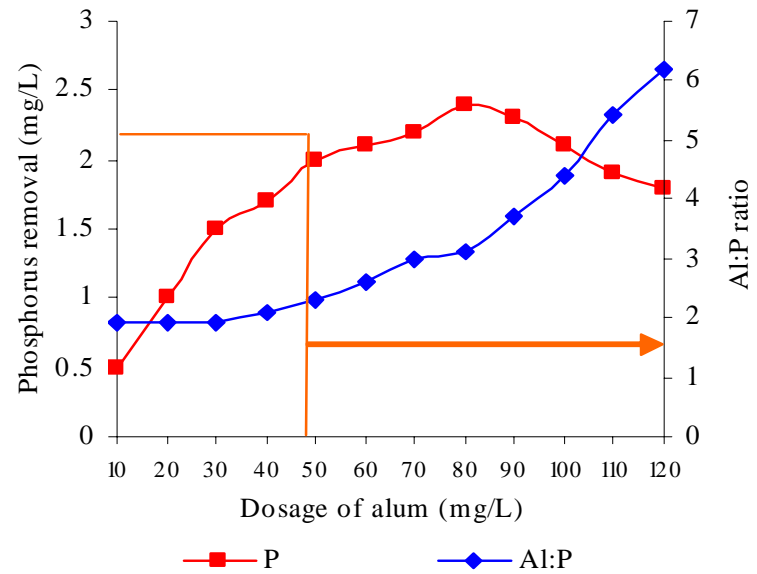

Fig. 5: The influence of alum dosage of phosphorus removal and mole ratio

the results were depicted in Fig. 4. This figure shows that the small particles settle out quickly within the first $5 \mathrm{~min}$., with little change in the values up to $15 \mathrm{~min}$. The differences in TP, COD and TSS removal were not significant after $20 \mathrm{~min}$. of settling. Thus, it was decided to keep a settling time of $20 \mathrm{~min}$. for further experiments.

After optimizing the parameters for low alkalinity wastewater, the tests were conducted in the optimized condition of $\mathrm{pH} 7$ to find out the treatment efficiency. From Fig. 5, it is evident that the phosphorus removal increases with an increase in the alum dosage. The removal starts decreasing when the dosage increases from $80 \mathrm{mg} / \mathrm{L}$ to $90 \mathrm{mg} / \mathrm{L}$, limiting the application of coagulant. The theoretical mole ratio for the phosphorus removal using aluminum is 1:1. However, it is never achieved in practice and the actual ratio between aluminum dosed and phosphorus removed is always higher than 2 (De Hass, et al., 2000). Although the presently observed ratio of 2.3 mole of aluminum per mole of phosphorus was higher than theoretical calculation, it was comparatively lower than the value of 4.13 and 3 reported by Wang, et al., (2005) and Xie, et al., (2005), respectively, for the secondary treated wastewater. Table 1 presents data on treatment efficiency of aluminum at 2.3:1 mole ratio dosages. In addition to the phosphorus removal, coagulant also removed other parameters significantly.

An evaluation of the coagulant alum for treating low alkalinity wastewater was conducted using the standard jar test procedures. After adding coagulant, the $\mathrm{pH}$ of the wastewater acts as a limiting factor for phosphorus removal. When the $\mathrm{pH}$ is 5.7-5.9, further
Table 1: Physico-chemical charactertistic of secondary treated domestic wastewater

\begin{tabular}{llc}
\hline Parameters & Influent & $\begin{array}{c}\text { Treated at Al:P }= \\
2.3: 1 \text { mole ratio }\end{array}$ \\
\hline $\mathrm{pH}^{*}$ & $6.6-6.7$ & 5.8 \\
TP-P & 2.9 & 0.3 \\
TP (soluble) & 2.7 & 0.2 \\
$\mathrm{PO}_{4}{ }^{-3}$ & 8 & 0.9 \\
$\mathrm{COD}$ & 8 & 0 \\
$\mathrm{COD}(\mathrm{S})$ & 3 & 0 \\
$\mathrm{BOD}$ & 3 & 0 \\
$\mathrm{SS}$ & 8.5 & 1.2 \\
TN & 17.1 & 8 \\
Alkalinity, as $\mathrm{CaCO}_{3}$ & 50 & 13 \\
\hline
\end{tabular}

*all are in $\mathrm{mg} / \mathrm{L}$, except $\mathrm{pH}$

addition of coagulant reduces the removal efficiency. A decrease in the $\mathrm{pH}$ below the range of 5.7-5.9 decreases the phosphorus removal efficiency. Further removal of the phosphorous by coagulation will just be possible through supplementation of alkalinity. Slow mixing and settling time were optimized and found to be 20 min. The optimum mole ratio to remove 1 mole of the phosphorus using alum coagulant was found to be 2.3. Future studies focusing on simultaneous precipitations for low alkalinity wastewater are also in progress.

\section{ACKNOWLEDGEMENTS}

This study is a part of the Brain Korea 21 (BK-21) program supported by the Korean Ministry of Education.

\section{REFERENCES}

Ahmad, A. L.; Sumathi, S.; Hameed, B. H., (2006). Coagulation of residue oil and suspended solid in palm oil mill effluent by chitosan, alum and PAC. Chem. Eng. J., 118, 99-105.

APHA (2005). Standard Methods for the Examination of Water and Wastewater., 21 $1^{\text {st. }}$ Ed., American Public Health Association, American Water Works Association, Water Pollution and Control Federation, Washington, DC.

Clark, T.; Stephenson, T.; Pearce, P. A., (1997). Phosphorus removal by chemical precipitation in a biological aerated filter. Water Res., 31(10), 2557-63.

De Hass, D. W.; Wentzel, M. C.; Ekama, G. A., (2000). The use of simultaneous chemical precipitation in modified activated sludge systems exhibiting biological excess phosphate removal Part 1: Literature review. Water SA., 26(4), 439452.

Georgantas, D. A.; Grigoropoulou, H. P., (2006). Phosphorus and organic matter removal from synthetic waster using alum and aluminum hydroxide. Global NEST J., 8(2), 121-130.

James, M.; Ebeling Sibrell, P. L.; Ogden, S. R.; Steven, S. T., (2003). Evaluation of chemical coagulation-flocculation aids for the removal of suspended solids and phosphorus from 
intensive recirculating aquaculture effluent discharge. Aquacult. Eng., 29, 23-42.

Lee, S. I.; Weon, S. Y.; Lee, C. W.; Koopman, B., (2003). Removal of nitrogen and phosphate from wastewater by addition of bittern. Chemosphere, 51, 265-271.

Lujubinko, L.; Julianna, G.; Mirjana, D.; Tatjana, K., (2004). Optimization of $\mathrm{pH}$ value and aluminium sulphate quantity in the chemical treatment of molasses. Eur. Food Res. Tech., 220, 70-73.

Mahmut, O.; Ayhan, S., (2003). Effect of tannins on phosphate removal using alum. Turkish J. Eng. Environ. Sci., 27, 227236.

Mervat, E.; Logan, A. W., (1996). Removal of phosphorus from secondary effluent by a matrix filter. Desalination, 106, 247-253.

Metcalf and Eddy, (1993). Wastewater engineering treatment disposal and reuse. McGraw-Hill, USA.

Muller, J. A.; Palonen, H., (2002). Optimisation of floc stability by mechanical pre and post stressing. IWA publishing, UK., 7, 297-308.

Paul, E.; Laval, M., L.; Sperandio, M., (2001). Excess sludge production and cost due to phosphorus removal. Environ. Tech., 22, 1363-1371.

Pinotti, A.; Zaritzky, N., (2001). Effect of aluminum sulfate and cationic polyelectrolytes on the destabilization of emulsified wastes., Waste Manage. 21(6), 535-542.

Plaza, E.; Levlin, E.; Hultman, B., (1997). Phosphorus removal from wastewater-a literature review. Division of Water Resources Engineering, Department of Civil and
Environmental Engineering, Royal Institute of Technology, Stockholm.

Robert, J.; Takashi, S.; Motoharu, M., (2003). The microbiology of biological phosphorus removal in activated sludge systems. Microbiol. Rev., 27, 99-127.

Sedlak, R., (1991). Phosphorus and nitrogen removal from muuicipal wastewater: Principles and practice. Lewis publishers, USA.

Stanley, E. M., (2001). Fundamentals of environmental chemistry. CRC Press, London.

Vernon, L. S.; David, J., (1980). Water chemistry. John Wiley and Sons, USA.

Wang, X. J.; Xia, S. Q.; Chen, L.; Zhao, J. F.; Renault, N. J.; Chovelon, J. M., (2006). Nutrients removal from municipal wastewater by chemical precipitation in a moving bed biofilm reactor. Proc. Biochem., 41, 824-828.

Wang, Y.; Han, T.; Xu Bao, G.; Tan, Z., (2005). Optimization of phosphorus removal from secondary effluent using simplex method in Tianjin, China. J. Hazard. Mater., 21, 183-186.

Xie, W.; Qunhui, W.; Hongzhi, M.; Yukihide, O.; Hiroaki, I. O., (2005). Study on phosphorus removal using a coagulation system. Proc. Biochem., 40, 2623-2627.

Yeoman, S.; Stephenson, T.; Lester, J. N.; Perry, R., (1988). The removal of phosphorus during wastewater treatment: a review. Environ. Pollut., 49, 183-233.

\section{AUTHOR (S) BIOSKETCHES}

Yeom, I. T., Ph.D., Professor in the Department of Civil and Environmental Engineering, Sungkyunkwan University, Korea. Email: yeom@skku.edu

Banu, R. J., Ph.D., Post Doctoral fellow in the Department of Civil and Environmental Engineering, Sungkyunkwan University, Korea. Email: rajeshces@gmail.com

Do, K. U., M.Sc., Doctoral fellow in the Department of Civil and Environmental Engineering, Sungkyunkwan University, Korea. Email: dokhacuan@yahoo.com

This article should be referenced as follows:

Yeom, I. T.; Banu, R. J.; Do, K. U. (2008). A study on phosphorus removal in low alkalinity secondary effluent using alum. Int. J. Environ. Sci. Tech., 5(1), 93-98. 